DR. ANGELO SANGIOVANNI (Orcid ID : 0000-0002-9996-9385)

DR. MASSIMO IAVARONE (Orcid ID : 0000-0003-3493-6504)

DR. VINCENZO LA MURA (Orcid ID : 0000-0003-4685-7184)

PROF. MASSIMO GIUSEPPE COLOMBO (Orcid ID : 0000-0002-7856-1268)

DR. PIETRO LAMPERTICO (Orcid ID : 0000-0002-1026-7476)

Article type : Original Articles

Editor : Morris Sherman

\title{
MULTIMODALITY TREATMENT OF HEPATOCELLULAR CARCINOMA: HOW FIELD PRACTICE COMPLIES WITH INTERNATIONAL RECOMMENDATIONS
}

Angelo Sangiovanni ${ }^{1}$, Michela Triolo ${ }^{2}$, Massimo lavarone ${ }^{1}$, Laura Virginia Forzenigo ${ }^{3}$, Antonio Nicolini ${ }^{4}$, Giorgio Rossi ${ }^{5}$, Vincenzo La Mura ${ }^{6}$, Massimo Colombo ${ }^{7}$, Pietro Lampertico ${ }^{1}$

1) Division of Gastroenterology and Hepatology, "A.M. and A. Migliavacca"Center for Liver Disease, Fondazione IRCCS Ca' Granda Ospedale Maggiore Policlinico, University of Milan, Milan, Italy.

2) Division of Internal Medicine, Policlinico S. Donato, University of Milan, San Donato Milanese, Italy.

3) Division of Radiology, Fondazione IRCCS Ca' Granda Ospedale Maggiore Policlinico, Milan, Italy.

4) Division of Interventional Radiology, Fondazione IRCCS Ca' Granda Ospedale Maggiore Policlinico, Milan, Italy.

This article has been accepted for publication and undergone full peer review but has not been through the copyediting, typesetting, pagination and proofreading process, which may lead to differences between this version and the Version of Record. Please cite this article as doi: 10.1111/liv.13888

This article is protected by copyright. All rights reserved. 
5) Division of Surgery and Liver Transplant, Fondazione IRCCS Ca' Granda Ospedale Maggiore Policlinico, University of Milan, Milan, Italy.

6) Internal Medicine Hemostasis and Thrombosis Division, Biomedical Sciences for Health Department, Fondazione IRCCS Ca' Granda Ospedale Maggiore Policlinico, University of Milan, Milan, Italy

University of Milan, Ospedale Maggiore Policlinico, Fondazione IRCCS Ca' Granda, Milan, Italy

7) Department of Medicine and Hepatology, Humanitas clinical and research center, Rozzano, Italy.

\section{Corresponding author:}

Angelo Sangiovanni MD

Division of Gastroenterology and Hepatology, "A.M. and A. Migliavacca” Center for Liver Disease, Fondazione IRCCS Ca' Granda Ospedale Maggiore Policlinico

University of Milan

Via F. Sforza 35

20122 Milan - ITALY

Tel 39-0255035432 Fax 39-0250320410

E-mail: angelo.sangiovanni@policlinico.mi.it

Running Title: Multimodality treatment of HCC

\section{List of abbreviations:}

$\mathrm{HCC}=$ hepatocellular carcinoma

MDT = multidisciplinary Team

AASLD = American Association for the Study of Liver Diseases

This article is protected by copyright. All rights reserved. 
EASL = European Association for the Study of Liver Diseases

EORTC $=$ European Organization for Research and Treatment of Cancer

$\mathrm{LT}=$ liver transplantation

TACE $=$ transarterial chemoembolization

AFP = alpha-fetoprotein

INR = prothrombin time

PSE = portosystemic encephalopathy

FNB = fine needle biopsy

$\mathrm{PEI}=$ percutaneous alcohol injection

RFTA $=$ radiofrequency ablation

ECOG PS = Eastern Cooperative Oncology Group Performance Status

NCCN $=$ National Comprehensive Cancer Network

\section{Financial disclosures}

Angelo Sangiovanni: speaker bureau for Bayer, Gilead Science, Janssen, BTG, Abbvie, Novartis, Advisory board for Tiziana science.

Massimo lavarone: speaker bureau for Bayer, Gilead Science, Janssen, BTG, Abbvie, consultant for BTG

Massimo Colombo: Grant and research support: BMS, Gilead Science. Advisory committees: Merck, Roche, Novartis, Bayer, BMS, Gilead Science, Tibotec, Vertex, Janssen Cilag, Achillion, Lundbeck, GSK, GenSpera, AbbVie, AlfaWasserman, Jennerex. Speaking and teaching: Tibotec, Roche, Novartis, Bayer, BMS, Gilead Science, Vertex, Merck, Janssen, Sanofi

Pietro Lampertico: advisor and speaker bureau for Gilead, Roche, BMS, GSK, MSD, Arrowhead, Alnylam

\section{Conflict of Interest}

All the authors do not have conflict of interests.

This article is protected by copyright. All rights reserved. 


\section{Author contributions}

AS managed the conception and design; $\mathrm{AS}, \mathrm{MT}, \mathrm{MI}$, were responsible for clinical management of patients; LVF performed radiological evaluation; AN was responsible for interventional radiology treatments; GR was responsible for surgical treatments; MT, collected data; AS, VLM analyzed data; AS, MT wrote manuscript; MC, PL reviewed intellectual content.

\section{ABSTRACT}

Background: Management of hepatocellular carcinoma (HCC) is framed within standardized protocols released by Scientific Societies, whose applicability and efficacy in field practice need refining.

Aim: We evaluated the applicability and effectiveness of guidelines for the treatment of HCC of the American Association for the Study of the Liver (AASLD).

Methods: 370 consecutive cirrhotic patients with de-novo HCC in different stages (253 BCLC A, 66 BCLC B, 51 BCLC C) received treatment through a multidisciplinary team (MDT) decision and were followed until death or end of follow-up.

Results: Adherent treatment to AASLD recommendations was in 205 (81\%) BCLC A patients, 36 (54\%) BCLC B, and 27 (53\%) BCLC C. Radiological complete response was achieved in 165 (45\%) patients after the first-line treatment, in 22 (19\%) after a second-line and in 9 (23\%) after a third line treatment. Adherence to AASLD recommendation allowed a lower yearly mean mortality rate in BCLC A patients compared to other treatment $(5.0 \%$ vs $10.4 \% \mathrm{p}=$ 0.004), whereas upward treatment stage migration compared to the standard of care was associated to reduced yearly mortality in BCLC B $(8.6 \%$ vs $20.7 \%, p=0.029)$ and BCLC C (42.6\% vs $59.0 \%, \mathrm{p}=0.04)$ patients.

This article is protected by copyright. All rights reserved. 
Conclusions: HCC multimodality treatment including other than first-line therapy is common in clinical practice and impact on the achievement of complete response. Personalized treatment was able to provide survival benefits to patients whose profile is not accounted for by international recommendations, which need to be amended.

Keywords: hepatocellular carcinoma, BCLC stage, HCC treatment, cirrhosis

\section{Key points}

- Multimodality treatment of HCC in the field practice in a tertiary referral center was reported.

- Discrepancies from 2011 AASLD recommendations in HCC patients management were detailed. Outcome of second-, third- and forth-line HCC treatments, never considered in the AASLD recommendation, was reported.

- Evidence of an increased survival for HCC treatment according to upward stage migration as compared to AASLD recommended treatment was reported in BCLC B and C patients.

- Independent prognostic factors for BCLC A, B and C class were reported.

\section{INTRODUCTION}

Survival of patients with a hepatocellular carcinoma (HCC) largely depends on patient access to potentially curative therapies as dictated by disease stage classification based on tumor burden, liver impairment and performance status ${ }^{1-3}$. The multidimensional BCLC staging system which has been endorsed by the American (AASLD) and European (EASL) Associations for the Study of Liver Diseases and the European Organization for Research and Treatment of Cancer (EORTC), serves the purpose ${ }^{4-7}$. Liver transplantation (LT), surgical resection and local ablation have emerged as most effective options which provide significant survival benefits to patients with an early tumor (BCLC 0/A). Unfortunately, this is not the case for the many patients harboring a greater tumor burden confined to the liver (intermediate stage BCLC B), who are not indicated to radical treatments but may still gain survival benefits by local treatments with transarterial chemoembolization (TACE). Finally, survival can still be improved in patients with advanced stage (BCLC C) tumor, following oral treatment with the multikynase inhibitor sorafenib. ${ }^{4-7}$ In real life, however, adherence to the therapeutic algorithms for HCC recommended by international societies may be 
compromised by scarcity of liver donors for LT, strategic localization of an early tumor and presence of co-morbidities which unbalance the risk benefit ratio of non transplant curative treatments. $^{7-9}$ Not surprisingly, therefore, TACE has gained popularity as a back-up treatment modality for an appreciable number of BCLC A patients who are unfit to radical therapies,. On the other hand relaxed criteria of selection have been applied to some BCLC $B$ or $C$ patients who ultimately underwent radical treatments in the case of tumor easily accessible, responsive to downstaging or accompanied by limited neoplastic thrombosis confined to peripheral branches of portal vein close to the tumor nodule. While the adherence to international guidelines for HCC treatment is far from being worldwide applied, ${ }^{7,10-16}$ there is scanty data on the outcome of HCC patients treated under the guidance of a multidisciplinary team (MDT), irrespective whether the patient adheres or not to AASLD guidelines. As a matter of fact, there is evidence of survival benefits provided by therapy of HCC outside the guidelines according to the migration stage concept, while data is limited on the impact of sequencing treatment following the first-line therapy.

We therefore aimed to retrospectively evaluate the outcome of HCC treatment with respect to AASLD guidelines in consecutive patients attending a tertiary referral center, characterize predictors of outcome in patients treated out of guidelines and evaluate the impact of sequencing treatment after first-line therapy.

\section{MATERIAL AND METHODS}

Between January 2007 and December 2011, 280 consecutive cirrhotic patients with a de novo HCC diagnosed at the Center for Liver Disease, Fondazione IRCCS Cà Granda Ospedale Maggiore Policlinico, Milan, and 90 referred from General Practitioner or other Centres for the characterization of liver nodules, were enrolled in this observational longitudinal study and followed until death or last follow-up available up to December 2016. Patients with a previous diagnosis of liver cancer and those with poor liver function (Child-Pugh C), were excluded.

After providing an informed consent, patients were enrolled following the collection of medical history, physical examination, complete blood count and biochemical tests. Etiology was classified as: HBV for serum HBsAg positivity, HCV for anti-HCV positivity, alcohol for alcohol intake higher than $60 \mathrm{~g} /$ day in male and $40 \mathrm{~g} /$ day in female for more than 10 years, mixed when more than one etiologic factor was recorded, other for autoimmune, metabolic, genetic etiology. All HBV patients were on antiviral therapy with nucleos(t)ide analogs. All HCV patients had serum HCV-RNA detectable. Clinical data were managed according to current Italian legislation for privacy, all personal data being blinded in the database. Cirrhosis was diagnosed either by histology or unequivocal clinical signs. HCC was diagnosed according to AASLD criteria. ${ }^{4,5}$ A US-guided fine-needle biopsy (FNB) was

This article is protected by copyright. All rights reserved. 
performed to characterize nodules escaping radiological diagnosis, using a 21-gauge needle (Biomol, HS Hospital Service S.P.A., Aprilia, Italy).

At enrollment, all patients underwent staging with a chest-CT scan and bone scintigraphy, and were stratified for HCC stage according to BCLC classification. ${ }^{1-3,17}$ Treatment modality was guided by a MDT composed by a transplant surgeon, a hepatologist and an interventional radiologist. Intention-to-treat decision was made according to the AASLD recommendations for $\mathrm{HCC}^{4,5}$. Radio frequency ablation (RFTA) was the first choice for tumor ablation, whereas alcohol injection (PEI) was a possible alternative in nodules up to $2 \mathrm{~cm}$. Patients listed to LT were bridged with RFTA or TACE, in any case considering LT as the firstline treatment in the analysis. Response to therapy was defined by modified RECIST criteria $^{18}$ performing a CT or MRI one month apart local ablation and each cycle of TACE, two months apart resection, $L T$ and first administration of sorafenib. Patients achieving a radiological complete response repeated a CT or MRI every three months for 24 months and subsequently were switched to US surveillance at 6 month intervals.

In patients unfitting treatment criteria suggested by AASLD recommendations upward or downward stage migration was proposed. An upward stage migration were decided in the case of easy access to the upward treatment (i.e., HCC satellites $<1 \mathrm{~cm}$ close to the main nodules, more than one nodule in the same liver segment suitable for resection, easy videolaparoscopic access to the nodule even in the case of portal hypertension, marginal neoplastic portal vein thrombosis close to tumor nodule). We considered downward stage migration in the case of severe comorbidities, advanced age, strategical localization of the nodules. hypovascular pattern hindering chemoembolization, refusal to the proposed treatment.

Retreatment of patients who failed to achieve a complete response was decided by MDT as follows: RFTA was repeated once in patients with incomplete tumor necrosis; TACE was repeated until complete response or demonstrated progression. Sorafenib dose was reduced by $50 \%$ in case of grade 2 toxicity whereas it was discontinued whenever tumor progressed or grade 3-4 side-effects did not improve following 7 days discontinuation.

A second-line treatment was proposed by MDT for patients with tumor progression, or unfit to further cycles of first-line treatment due to technical constraints, like failure of catheterization of the feeding artery, residual tumor not manageable with the first-line treatment, or tumor recurrence. The same policy was adopted for third-and forth line treatments. Patients were restaged and BCLC recalculated before each line of treatment. Patients were followed until death or last available clinical evaluation, up to January 2014.

Patients treated out of AASLD guidelines were split between those who underwent therapies offered to the next best or to the next worst stage, and the outcome compared to that of patients treated according to the standard of care.

This article is protected by copyright. All rights reserved. 
The study was performed in agreement with the 1975 Declaration of Helsinki and it was approved by ethic committee Milano area B.

\section{Statistical analysis}

The baseline characteristics of the patients are expressed as median and range or count and proportion. Characteristics of patients treated according to or out of AASLD recommendation were compared by chi-square test and Student's t-test. Estimated survival function was calculated by the Kaplan-Meier method and survival curves were compared by log-rank test. All information about variables were collected the time of enrollment. Variables considered for univariate analysis were: age, gender, performance status (PS), number of HCC nodules, maximum diameter of HCC nodules, portal vein neoplastic infiltration, ascites, porto-systemic encephalopathy (PSE), prothrombin time (INR), serum AFP, bilirubin, albumin, creatinine, etiology of the underling chronic liver disease, concordance to AASLD therapeutic algorithm. The median value of continuous variables such as age, albumim creatinine, bilirubin, PT (INR) were the cut-off points used to generate two groups of patients. The same criteria were applied for BCLC A, B and C patients. Different cut-off points were defined for each BCLC stage. The univariate analysis and the Cox proportional hazards regression were used to evaluate overall survival in the whole series of patients and repeated for each BCLC stage. Variables with a p-value less than 0.10 at univariate analysis were introduced in the Cox model. To evaluate the influence on survival of the disagreement to AASLD guidelines in the MDT treatment decision, characteristics of patients treated according to or out off guidelines were compared and the Cox model was repeated adjusting for those variables related to liver function with a $p$-value less than 0.10. To reduce possible colinearities, redundant variables were not introduced in the final model of multivariate analysis. A $p$ value $<0.05$ was considered statistically significant. Calculations were done with the Stata 10.0 statistical package (Stata, College Station, Texas, USA).

\section{RESULTS}

The study population included 370 patients, 280 (76\%) who were identified through the hospital program of US surveillance and 90 (24\%) who had been referred from other hospitals or general practitioners. All patients had cirrhosis and a majority were in early stage BCLC A (Table 1). HCC was radiologically diagnosed in 239 (65\%) patients and histologically in the remaining 131 (35\%). Serum AFP level was $\leq 20 \mathrm{ng} / \mathrm{mL}$ in 225 (61\%) whereas it was greater than $200 \mathrm{ng} / \mathrm{mL}$ in 54 (15\%) patients, only.

This article is protected by copyright. All rights reserved. 
Treatment algorithm

The first line therapy was any radical treatment in 234 (63\%) patients, TACE in 90 (24\%), systemic medical treatment in $34(9 \%)$ and BSC in 12 (3\%) (Table 2). TACE was a bridge therapy in additional 7 (2\%) patients listed to LT. Overall, a first line treatment adherent to AASLD recommendations was performed in 268 (72\%) patients, including 205 (81\%) BCLC 0A, 36 (54\%) BCLC B, and 27 (53\%) BCLC C patients. Radical therapies were offered to 22 (34\%) BCLC B and 7 (14\%) BCLC C, TACE to 46 (18\%) BCLC A patients and 8 (16\%) BCLC C, sorafenib to $1(0.5 \%)$ BCLC A and 6 (9\%) BCLC B, BSC to 1 (0.5\%) BCLC A, 2 (3\%) BCLC B and 9 (17\%) BCLC C. Discrepant treatments from AASLD recommendations were $48(19 \%)$ in BCLC 0-A, 30 (45\% BCLC B, 24 (47\%) BCLC C. Details on applied treatment and reason for discrepancies from AASLD recommendations are reported in Table 3.

One hundred-seventeen (32\%) patients with HCC progression received a second-line treatment as did patients with a partial response, stable disease or residual tumor who were judged by MDT to be no longer fit to first-line therapies. Thirty-nine (11\%) and $9(2 \%)$ patients were offered a third-line and a fourth-line treatment, respectively (Table 2). Restaging for patients proposed for treatment following the first line therapy is showed in Figure 1. Overall, a complete response was obtained in 186 (50\%) patients, 165 (45\%) after a first-line treatment, 22/117 (19\%) after a second-line treatment, and 9/39 (23\%) after a third-line treatment. Thirteen patients (3\%) achieved a complete response more than one time. Overall, second-third and forth line of treatment achieved a complete response in $31 / 370$ (8\%) patients.

HCC recurred in 6 (17\%) of the 36 transplanted patients: 2 BCLC A4 who received LT as firstline treatment, $2 \mathrm{BCLC} A 4$ and $2 \mathrm{BCLC} B$ who received $\mathrm{LT}$ as rescue therapy after resection.

\section{Survival}

During a median follow-up of 25 months (range 1-149), 105 (28\%) patients died, 41 (16\%) BCLC A, 25 (38\%) BCLC B and 39 (74\%) BCLC C. Along the same period 5 (1\%) patients were lost (4 in BCLC A, and 1 in BCLC C).

The mean yearly mortality rate of the overall cohort was $11.5 \%$, corresponding to a $1,3,5$ year overall survival of $92 \%, 69 \%$, and $58 \%$ respectively. The mean mortality rate was $5.9 \%$ in $\mathrm{BCLC} A, 16.4 \%$ in $\mathrm{BCLC} B$, and $57.0 \%$ in $\mathrm{BCLC}$. The corresponding $1,3,5$ year survival rates were $99 \%, 84 \%$ and $72 \%$ in BCLC A, 95\%, 55\%, 42\% in BCLC B and $58 \%, 13 \%, 6 \%$, in $B C L C$, respectively (Figure 2). In BCLC $A$ the mean mortality rate was lower in patients treated according to AASLD recommendations than in patients otherwise treated $(5.0 \%$ vs $10.4 \%$, respectively, $\mathrm{p}=0.004$ ), corresponding to a $1,3,5$ year survival of $100 \%, 86 \%, 77 \%$ vs $93 \%, 75 \%, 47 \%$ respectively (Figure 3a). The treatment migration to a better stage was associated to a lower mortality rate as compared to standard of treatment in BCLC B $(8.6 \%$

This article is protected by copyright. All rights reserved. 
vs $20.7 \%, p=0.029$ ) corresponding to a $1,3,5$ year survival of $100 \%, 74 \%, 67 \%$ vs $100 \%$, $43 \%, 23 \%$, respectively (Figure 3b), as well as in BCLC C (42.6\% vs 59\%, $p=0.04), 1,3,5 \mathrm{yr}$ survival $79 \%, 39 \%, 0 \%$ vs $42 \%, 1 \%, 0 \%$, respectively (Figure $3 \mathrm{c}$ ). On the other hand in BCLC B and in BCLC C stage no significant differences were observed between patients treated according to recommendation and those treated with a treatment migration to a lower stage (mean mortality rate $36.9 \%$ in BCLC B and $50.4 \%$ in BCLC C, $p=0.10$ and $p=0.5$ respectively).

Table 4 reports predictors of survival by univariate analysis in the whole series of patients and according to BCLC stage. By multivariate analysis, independent predictors of survival were performance status (H.R. $4.0,95 \%$ C.I. 1.8-9.0, $p=0.001$ ), number of the nodules (H.R. 1.1, 95\% C.I. 1.0-1.2, p<0.001), maximum diameter of the nodules (H.R. 1.7, 95\% C.I. 1.3-2.3, p<0.001), neoplastic portal vein thrombosis (H.R $2.6,95 \%$ C.I. 1.3-4.5, p=0.006), ascites (H.R. 2.4, 95\% C.I. 1.5-3.9, p<0.001), and AFP (H.R. 1.8, 95\% C.I. 1.4-2.4, p < 0.001) (Table 5). The same table reports results of multivariate analysis performed in each BCLC stage. Independent predictors of mortality were maximum diameter of the nodules (H.R. 1.9, 95\% C.I. 1.2-3.1, $p=0.008$ ), presence of ascites (H.R. 2.0, 95\% C.I. 1.0-4.1, $p=0.05$ ) and concordance to AASLD guidelines (H.R. 2.8, 95\% C.I. 1.3-5.8, $p=0.006$ ) in BCLC A, AFP (HR 2.7, 95\% C.I. 1.6-4.5, $\mathrm{p}=0.001$ ) and concordance to AASLD guidelines (H.R. 2.9, 1.5-5.5, $p=0.002$ ) in $B C L C B$, while no independent predictors were detected in BCLC C.

\section{DISCUSSION}

We aimed to assess to which extent adherence to AASLD recommendations impacts on the outcome of treatment of HCC in a cohort of patients mirroring the general population attending any referral center for liver disease in Italy. ${ }^{19-21}$ However, in our study the proportion of patients undergoing follow-up and some therapies was higher than in other cohorts referred to multicentric studies of the same geographic area ${ }^{22,23}$. This could represent an indirect evidence of benefits determined by having access to all the therapeutic options, including OLT, as a tertially referral centre. Nevertheless, taking the AALSD recommendations as our standard of care for HCC, $28 \%$ of our patients ultimately failed to receive the recommended treatment to the point that even in the best prognostic group (BCLC 0-A), 19\% of patients missed any radical treatment. This finding suggests that despite International Guidelines are accepted and embedded in the clinical practice, violations cannot be prevented ${ }^{24}$, even in the presence of academic professionals in a MDTs. ${ }^{25}$ Our practice resulted in lower rates of guidelines violations compared to $24 \%$ in BCLC 0 and $36 \%$ in BCLC A reported in an academic Hospital in South Korea ${ }^{14,} 46 \%$ in BCLC 0A patients treated in an academic center ${ }^{15}$ in Italy, $34 \%$ in Spain ${ }^{26}$ and Egypt ${ }^{16}$, and to $40 \%$ rates in BCLC 0-A patients attending primary care hospitals ${ }^{8}$ in Italy.

This article is protected by copyright. All rights reserved. 
Not surprisingly, a major reason for a suboptimal adherence to AASLD guidelines was the prevalence of severe co-morbidities and strategic tumor localization, two variables of prognostic value that in fact are overlooked in the BCLC staging system.

In our setting, while a radiological complete response was achieved in the $66 \%$ of BCLC $0-A$ patients treated according to AASLD recommendations, the success rate was $28 \%$ only in patients treated out of guidelines, thereby causing more patients to require additional treatments. This translated in a significant difference in survival, with $77 \%$ of BCLC $0-A$ patients treated according to AASLD guidelines surviving at 5 years compared to $47 \%$ of patients who received off recommendations treatments. This survival rate was quite similar to that reported in literature for patients treated in the same stage, ranging between 40$70 \% .{ }^{6}$ Enforcing the concept of treatment stage migration, it was no surprise to find that $B C L C$ B patients receiving radical therapies had a better outcome compared to patients treated with TACE $(p=0.029)$, which represents the standard of care for this stage. This observation does not devalue the evidence-based guideline appropriateness, but highlights the added value of MDT which considers variables not included in the BCLC recommendations. It is well known that BCLC B stage include a wide clinical heterogeneity ${ }^{27}$, therefore, it can be expected that some intermediate-stage patients may benefit from treatments other than TACE, including resection and ablation, as suggested by the Japanese society and the National Comprehensive Cancer Network. ${ }^{28,29}$ On the other hand, the outcome of treatment did not worsen when patients were shifted to the SOC treatment options for a more advanced stages, probably as a consequence of the low number patients included. The evidence that concordance to the guidelines resulted as an independent predictor of survival could be a consequence of the heterogeneity in BCLC B stage. Not surprisingly, in a such wide motely stage, also AFP, a well-recognized marker of tumor dedifferentiation, was an independent predictor of survival, a data which speaks in favor of tumor biology as a relevant determinant of prognosis.

Whereas the multivariate analysis failed to identify any predictors of survival in BCLC C patients, we underline that even in this stage some patients can benefit of treatment migration to the upper stage. This happened mainly in the case of patients classified in BCLC $C$ because of performance status 1 and/or peripheral neoplastic portal vein thrombosis, which "per-se" are not an absolute contraindication to TACE, or RFTA. We should not ignore that a favorable outcome of other than sorafenib treatments was reported in patients with advanced cancer by a retrospective study in France comparing TACE and sorafenib ${ }^{30}$ and by a multinational study with a surprisingly $31 \%$ rate of 5-year survival in 169 cirrhotic patients with advanced HCC who underwent hepatic resection. ${ }^{31}$ Our data support these observations. In fact, one third of our BCLC C patients underwent treatment migration to the next best stage, resulting in 1, 2, 3 year survival of $88 \%, 44 \%$, and $26 \%$ respectively, with a median survival of 23 months, significantly better than the $43 \%, 24 \%, 6 \%$, median survival of 9.5 months, observed in patients treated with sorafenib. For the sake of evidence-based

This article is protected by copyright. All rights reserved. 
medicine, however, it should be reiterated that both applicability and clinical benefits of other than sorafenib treatment modalities in BCLC C patients, need to be validated by a RCT.

Our study emphasizes the relevance of HCC therapy following to the first-line treatment, reporting the rate of complete response to the second-third and fourth lines. Our policy was to decide treatment lines after the first option, according to guidelines referred to posttreatment staging. As it happened for the first line, many therapies were dispensed out of guidelines. Whereas this policy is difficult to standardize, we underline the outstanding complete response rates reported in the $21 \%$ of patients who underwent a second line of therapy and in the $15 \%$ of those who underwent a third line, a finding mainly observed in BCLC A patients and even in $9 \%$ of BCLC B patients.

Whereas this study was not designed to provide an algorithm for the multimodality treatment of HCC, it clearly suggests the relevance of the multimodality approach, largely applied worldwide in the clinical practice.

In conclusion, we confirm discrepancies between field practice and therapeutic algorithms recommended by AASLD. HCC multimodality treatment including other than first line therapy is common in clinical practice and it impacts on the achievement of complete response. The same wide clinical heterogeneity of HCC patients may also impact on field practice as it may favor discrepancies with the treatment decision making process recommended by the guidelines released by International Societies. We highlighted criticisms in the recommendations for the treatment of patients in BCLC B and C classes, which need to be amended in prospective trials, to refine personalized treatment algorithms for HCC patients, whose clinical profile is not accounted for by International guidelines.

\section{REFERENCES}

[1] Llovet JM1, Brú C, Bruix J. Prognosis of hepatocellular carcinoma: the BCLC staging classification. Semin Liver Dis. 1999; 19:329-38.

[2] Forner A, Reig ME, de Lope CR, Bruix J. Current strategy for staging and treatment: the BCLC update and future prospects. Semin Liver Dis. 2010; 30:61-74.

[3] Forner A, Reig M, Bruix J. Hepatocellular carcinoma. Lancet. 2018 Jan 4. pii: S01406736(18)30010-2.

This article is protected by copyright. All rights reserved. 
[4] Bruix J, Sherman M. Practice Guidelines Committee, American association for the Study of Liver Diseases. Management of hepatocellular carcinoma. Hepatology 2005; 42:12081236.

[5] Bruix J, Sherman M. Management of hepatocellular carcinoma, an update. Hepatology 2011; 53: 1020-1022.

[6] European Association for the Study of the Liver; European Organization for Research and Treatment of Cancer. EASL-EORTC'clinical practice guidelines: management of hepatocellular carcinoma. J. Hepatol 2012; 56:908-943.

[7] Heimbach JK, Kulik LM, Finn RS et al. AASLD guidelines for the treatment of hepatocellular carcinoma. Hepatology. 2018; 67:358-380.

[8] Borzio M, Fornari F, De Sio I, et al. Adherence to American Association for the Study of Liver Diseases guidelines for the management of hepatocellular carcinoma: results of an Italian field practice multicenter study. Future Oncol. 2013;9:283-94.

[9] Varela M, Reig M, de la Mata M, et al. Treatment approach of hepatocellular carcinoma in Spain. Analysis of 705 patients from 62 centers. Med Clin (Barc). 2010;134:569-76.

[10]El-Serag HB, Siegel AB, Davila JA, et al. Treatment and outcomes of treating of hepatocellular carcinoma among Medicare recipients in the United States: a populationbased study. J Hepatol. 2006;44:158-166.

[11] Gish RG, Lencioni R, Di Bisceglie AM, et al. Role of the multidisciplinary team in the diagnosis and treatment of hepatocellular carcinoma. Expert Rev Gastroenterol Hepatol. $2012 ; 6: 173-85$.

[12] Guy J, Kelley RK, Roberts J, et al. Multidisciplinary management of hepatocellular carcinoma. Clin Gastroenterol Hepatol. 2012; 10:354-62.

This article is protected by copyright. All rights reserved. 
[13] Roayaie S, Jibara G, Tabrizian P, et al. The role of hepatic resection in the treatment of hepatocellular cancer. Hepatology 2015;62: 440-451.

[14] Kim KM, Sinn DH, Jung SH, et al. The recommended treatment algorithms of the BCLC and HKLC staging systems: does following these always improve survival rates for HCC patients? Liver Int. 2016; 36:1490-97.

[15] Leoni S, Piscaglia F, Serio I, et al. Adherence to AASLD guidelines for the treatment of hepatocellular carcinoma in clinical practice: experience of the Bologna Liver Oncology Group. Dig Liver Dis. 2014; 46:549-55.

[16] Alkhatib A, Gomaa A, Allam N, et al. Real Life Treatment of Hepatocellular Carcinoma: Impact of Deviation from Guidelines for Recommended Therapy. Asian Pac J Cancer Prev. 2015; 16(16):6929-34.

[17] Forner A, Llovet JM, Bruix J. Hepatocellular carcinoma. Lancet. 2012;379:1245-5.

[18] Eisenhauer EA, Therasse P, Bogaerts J et al. New response evaluation criteria in solid tumours: revised RECIST guideline (version 1.1). Eur J Cancer. 2009;45:228-47.

[19] Sangiovanni A, Del Ninno E, Fasani P, et al. Increased survival of cirrhotic patients with a hepatocellular carcinoma detected during surveillance. Gastroenterology. 2004;126:1005-14.

[20] Sangiovanni A, Manini MA, Iavarone M, et al. The diagnostic and economic impact of contrast imaging techniques in the diagnosis of small hepatocellular carcinoma in cirrhosis. Gut. 2010; 59:638-44.

[21]Fattovich G, Stroffolini T, Zagni I, Donato F. Hepatocellular carcinoma in cirrhosis: incidence and risk factors. Gastroenterology. 2004;127(5 Suppl 1): S35-50.

This article is protected by copyright. All rights reserved. 
[22] Farinati F, Giacomin A, Vanin V et al. Liver transplantation for hepatocellular carcinoma in clinical practice: the lesson from a 20-year multicentre experience in Italy. Eur J Gastroenterol Hepatol. 2012; 24:195-202.

[23] Del Poggio P, Olmi S, Ciccarese F et al. Factors that affect efficacy of ultrasound surveillance for early stage hepatocellular carcinoma in patients with cirrhosis. Clin Gastroenterol Hepatol. 2014;12:1927-1933.

[24] Park JW, Chen M, Colombo M et al. Global patterns of hepatocellular carcinoma management from diagnosis to death: the BRIDGE Study. Liver Int. 2015; 35:21552166.

[25] Chang TT, Sawhney R, Monto , et al. Implementation of a multidisciplinary treatment team for hepatocellular cancer at a Veterans Affairs Medical Center improves survival. HPB (Oxford). 2008; 10:405-11.

[26] D'Avola D, Iñarrairaegui M, Pardo F, et al. Prognosis of hepatocellular carcinoma in relation to treatment across BCLC stages. Ann Surg Oncol. 2011;18:1964-71.

[27] Bolondi L, Burroughs A, Dufour JF, et al. Heterogeneity of patients with intermediate (BCLC B) Hepatocellular Carcinoma: proposal for a subclassification to facilitate treatment decisions. Semin Liver Dis. 2012; 32:348-59.

[28] Kudo M, Izumi N, Kokudo N, et al. HCC Expert Panel of Japan Society of Hepatology Management of hepatocellular carcinoma in Japan: Consensus-Based Clinical Practice Guidelines proposed by the Japan Society of Hepatology (JSH) 2010 updated version. Dig Dis. 2011;29:339-64.

[29] Benson AB, D'Angelica MI, Abbott DE, et al. NCCN Guidelines Insights: Hepatobiliary Cancers, Version 1.2017. J Natl Compr Canc Netw. 2017;15:563-573. 
[30]Pinter M, Hucke F, Graziadei I, et al. Advanced-stage hepatocellular carcinoma: transarterial chemoembolization versus sorafenib. Radiology. 2012; 263:590-9.

[31] Torzilli G, Belghiti J, Kokudo N, et al. A snapshot of the effective indications and results of surgery for hepatocellular carcinoma in tertiary referral centers: is it adherent to the EASL/AASLD recommendations? An observational study of the HCC East-West study group. Ann Surg. 2013; 257:929-37.

This article is protected by copyright. All rights reserved. 
Table 1: Baseline characteristics of patients

\begin{tabular}{|c|c|c|c|c|}
\hline & Total & BCLC 0-A & BCLC B & BCLC C \\
\hline No. of patients & 370 & 253 & 66 & 51 \\
\hline Age, yr median (range) & $68(33-86)$ & $68(33-86)$ & $68(46-85)$ & $68(35-84)$ \\
\hline $30-39$ & $3(1 \%)$ & $1(1 \%)$ & - & $2(4 \%)$ \\
\hline $40-49$ & $21(6 \%)$ & $18(7 \%)$ & $3(5 \%)$ & - \\
\hline $50-59$ & $61(16 \%)$ & $44(17 \%)$ & $8(12 \%)$ & $9(18 \%)$ \\
\hline $60-69$ & $123(33 \%)$ & $83(33 \%)$ & $25(38 \%)$ & $15(29 \%)$ \\
\hline $70-79$ & $141(38 \%)$ & $98(39 \%)$ & $22(33 \%)$ & $21(41 \%)$ \\
\hline $80-89$ & $21(6 \%)$ & $9(3 \%)$ & $8(12 \%)$ & $4(8 \%)$ \\
\hline Male gender, No. & 272 (73\%) & $182(72 \%)$ & $45(68 \%)$ & $45(85 \%)$ \\
\hline \multicolumn{5}{|l|}{ Etiology, No. } \\
\hline HBV only & $33(9 \%)$ & $20(8 \%)$ & $9(14 \%)$ & $4(8 \%)$ \\
\hline HCV only & 217 (59\%) & $160(63 \%)$ & $30(45 \%)$ & $27(53 \%)$ \\
\hline Alcohol only & 41 (11\%) & $23(9 \%)$ & $10(15 \%)$ & $8(15 \%)$ \\
\hline Mixed * & $55(15 \%)$ & $34(14 \%)$ & $15(23 \%)$ & $6(11 \%)$ \\
\hline Others $* *$ & $24(6 \%)$ & $16(6 \%)$ & $2(3 \%)$ & $6(11 \%)$ \\
\hline Albumin, mg/dL, median (range) & $3.9(2.2-5.1)$ & $4.0(2.5-5.0)$ & $3.8(2.2-5.1)$ & $3.9(2.9-5.0)$ \\
\hline Bilirubin, mg/dL, median (range) & $1.1(0.1-8.2)$ & $1.0(0.2-4.1)$ & $1.2(0.1-3.1)$ & $1.3(0.1-8.2)$ \\
\hline INR, median (range) & $1.1(0.6-3.1)$ & $1.1(0.6-2.2)$ & $1.2(0.9-1.4)$ & $1.2(0.9-3.1)$ \\
\hline Creatinine, $\mathrm{mg} / \mathrm{dL}$, median (range) & $0.9(0.4-3.5)$ & $0.9(0.4-2.1)$ & $0.9(0.5-3.5)$ & $1.0(0.5-1.8)$ \\
\hline \multicolumn{5}{|l|}{ AFP, ng/mL, No. } \\
\hline$<20$ & 225 (61\%) & 177 (70\%) & $33(50 \%)$ & $15(28 \%)$ \\
\hline $20-200$ & $91(24 \%)$ & $57(23 \%)$ & $18(27 \%)$ & $16(30 \%)$ \\
\hline$>200$ & $54(15 \%)$ & $17(7 \%)$ & $15(23 \%)$ & $22(42 \%)$ \\
\hline Ascites, No. & $80(22 \%)$ & $39(16 \%)$ & $19(29 \%)$ & $22(42 \%)$ \\
\hline PSE, No. & $19(5 \%)$ & $8(3 \%)$ & $3(5 \%)$ & $8(15 \%)$ \\
\hline ECOG PS $=0$, No. & 360 (97\%) & $253(100 \%)$ & $66(100 \%)$ & $43(81 \%)$ \\
\hline \multicolumn{5}{|l|}{ Child-Pugh score, No. } \\
\hline$A$ & 285 (77\%) & 203 (81\%) & $45(68 \%)$ & $37(70 \%)$ \\
\hline B & $85(23 \%)$ & $48(19 \%)$ & $21(32 \%)$ & $16(30 \%)$ \\
\hline MELD score, (range) & $9.0(6-21)$ & $8.8(6-18)$ & $9.4(6-21)$ & $9.4(6-17)$ \\
\hline \multicolumn{5}{|l|}{ No. of nodules, No. } \\
\hline 1 & 205 (55\%) & $184(73 \%)$ & 0 & $21(40 \%)$ \\
\hline $2-3$ & $110(30 \%)$ & $67(27 \%)$ & $33(50 \%)$ & $10(19 \%)$ \\
\hline$>3$ & $55(15 \%)$ & 0 & $33(50 \%)$ & $22(41 \%)$ \\
\hline \multicolumn{5}{|l|}{ Diameter of nodules, cm, No. } \\
\hline$<3$ & $244(66 \%)$ & 198 (79\%) & $26(39 \%)$ & $20(38 \%)$ \\
\hline $3-5$ & $81(22 \%)$ & $42(17 \%)$ & $25(38 \%)$ & $14(24 \%)$ \\
\hline$>5$ & $45(12 \%)$ & $11(4 \%)$ & $15(23 \%)$ & $19(36 \%)$ \\
\hline Neoplastic portal thrombosis, No. & $24(6 \%)$ & 0 & 0 & $24 \quad(45 \%)$ \\
\hline
\end{tabular}

This article is protected by copyright. All rights reserved. 
* Mixed: $\mathrm{HBV}+\mathrm{HCV}=9, \mathrm{HBV}+\mathrm{HDV}=6, \mathrm{HBV}+$ Alcohol $=7, \mathrm{HCV}+$ Alcohol $=25, \mathrm{HBV}+\mathrm{HDV}+\mathrm{Alcohol}=2$, $\mathrm{HCV}+\mathrm{NASH}=1$,

$\mathrm{HCV}+$ Genetic Hemochromatosis = 1, NASH+Alcohol = 3, NASH+HCV =1, Alcohol+Genetic Hemochromatosis = 1

** Others: NASH $=12$, Cryptogenetic $=9$, Primary Biliary Cholangitis $=2$, Autoimmune $=1$

This article is protected by copyright. All rights reserved. 
Table 2: Radiological complete response (CR) rates to treatments applied according to BCLC classification

\begin{tabular}{|c|c|c|c|c|c|c|c|c|c|c|c|c|c|c|c|c|}
\hline \multirow{3}{*}{ Treatment } & \multicolumn{4}{|c|}{ First line } & \multicolumn{5}{|c|}{ Second line } & \multicolumn{3}{|c|}{ Third line } & \multicolumn{4}{|c|}{ Fourth line } \\
\hline & \multicolumn{4}{|c|}{ BCLC (CR/Total) } & \multicolumn{4}{|c|}{ BCLC (CR/Total) } & \multicolumn{4}{|c|}{ BCLC (CR/Total) } & \multicolumn{4}{|c|}{ BCLC (CR/Total) } \\
\hline & Total & $A$ & B & C & Total & $A$ & B & C & Total & A & B & C & Total & $A$ & B & C \\
\hline OLT & $\begin{array}{l}27 / 29 \\
(93 \%)\end{array}$ & $\begin{array}{l}24 / 26 \\
(92 \%)\end{array}$ & $\begin{array}{c}3 / 3 \\
(100 \%)\end{array}$ & $0 / 0$ & $\begin{array}{l}0 / 1 \\
(0 \%)\end{array}$ & $0 / 0$ & $\begin{array}{l}0 / 1 \\
(0 \%)\end{array}$ & $0 / 0$ & $\begin{array}{c}4 / 5 \\
(80 \%)\end{array}$ & $\begin{array}{c}4 / 4 \\
(100 \%)\end{array}$ & $\begin{array}{l}0 / 1 \\
(0 \%)\end{array}$ & $0 / 0$ & $\begin{array}{c}0 / 2 \\
(0 \%)\end{array}$ & $\begin{array}{c}0 / 2 \\
(0 \%)\end{array}$ & $0 / 0$ & $0 / 0$ \\
\hline Resection & $\begin{array}{l}39 / 59 \\
(66 \%)\end{array}$ & $\begin{array}{l}36 / 52 \\
(69 \%)\end{array}$ & $\begin{array}{c}3 / 6 \\
(50 \%)\end{array}$ & $\begin{array}{c}0 / 1 \\
(0 \%)\end{array}$ & $\begin{array}{c}4 / 7 \\
(57 \%)\end{array}$ & $\begin{array}{c}4 / 6 \\
(67 \%)\end{array}$ & $\begin{array}{c}0 / 1 \\
(0 \%)\end{array}$ & $0 / 0$ & $\begin{array}{c}1 / 1 \\
(100 \%)\end{array}$ & $\begin{array}{c}1 / 1 \\
(100 \%)\end{array}$ & $0 / 0$ & $0 / 0$ & $0 / 0$ & $0 / 0$ & $0 / 0$ & $0 / 0$ \\
\hline Local ablation & $\begin{array}{c}80 / 146 \\
(55 \%)\end{array}$ & $\begin{array}{c}76 / 127 \\
(60 \%)\end{array}$ & $\begin{array}{l}4 / 13 \\
(31 \%)\end{array}$ & $\begin{array}{c}0 / 6 \\
(0 \%)\end{array}$ & $\begin{array}{l}8 / 33 \\
(24 \%)\end{array}$ & $\begin{array}{c}4 / 22 \\
(18 \%)\end{array}$ & $\begin{array}{l}4 / 11 \\
(36 \%)\end{array}$ & $0 / 0$ & $\begin{array}{l}0 / 3 \\
(0 \%)\end{array}$ & $0 / 0$ & $\begin{array}{l}0 / 3 \\
(0 \%)\end{array}$ & $0 / 0$ & $0 / 0$ & $0 / 0$ & $0 / 0$ & $0 / 0$ \\
\hline TACE & $\begin{array}{l}19 / 90 \\
(21 \%)\end{array}$ & $\begin{array}{l}13 / 46 \\
(28 \%)\end{array}$ & $\begin{array}{c}5 / 36 \\
(14 \%)\end{array}$ & $\begin{array}{c}1 / 8 \\
(12 \%)\end{array}$ & $\begin{array}{l}10 / 53 \\
(19 \%)\end{array}$ & $\begin{array}{c}9 / 25 \\
(36 \%)\end{array}$ & $\begin{array}{l}1 / 23 \\
(4 \%)\end{array}$ & $\begin{array}{c}0 / 5 \\
(0 \%)\end{array}$ & $\begin{array}{c}4 / 14 \\
(28 \%)\end{array}$ & $\begin{array}{c}4 / 8 \\
(50 \%)\end{array}$ & $\begin{array}{c}0 / 4 \\
(0 \%)\end{array}$ & $\begin{array}{c}0 / 2 \\
(0 \%)\end{array}$ & $\begin{array}{c}0 / 2 \\
(0 \%)\end{array}$ & $0 / 0$ & $\begin{array}{c}0 / 2 \\
(0 \%)\end{array}$ & $0 / 0$ \\
\hline Sorafenib & $\begin{array}{l}0 / 34 \\
(0 \%)\end{array}$ & $\begin{array}{l}0 / 1 \\
(0 \%)\end{array}$ & $\begin{array}{l}0 / 6 \\
(0 \%)\end{array}$ & $\begin{array}{l}0 / 27 \\
(0 \%)\end{array}$ & $\begin{array}{l}0 / 23 \\
(0 \%)\end{array}$ & $\begin{array}{c}0 / 2 \\
(0 \%)\end{array}$ & $\begin{array}{l}0 / 3 \\
(0 \%)\end{array}$ & $\begin{array}{l}0 / 18 \\
(0 \%)\end{array}$ & $\begin{array}{l}0 / 16 \\
(0 \%)\end{array}$ & $0 / 0$ & $\begin{array}{l}0 / 9 \\
(0 \%)\end{array}$ & $\begin{array}{l}0 / 7 \\
(0 \%)\end{array}$ & $\begin{array}{c}0 / 5 \\
(0 \%)\end{array}$ & $\begin{array}{l}0 / 2 \\
(0 \%)\end{array}$ & $\begin{array}{c}0 / 2 \\
(0 \%)\end{array}$ & $0 / 0$ \\
\hline
\end{tabular}

This article is protected by copyright. All rights reserved. 


\begin{tabular}{|c|c|c|c|c|c|c|c|c|c|c|c|c|c|c|c|c|}
\hline BSC & $0 / 12$ & $0 / 1$ & $0 / 2$ & $0 / 9$ & & & & & & & & & & & & \\
\hline & $(0 \%)$ & $(0 \%)$ & $(0 \%)$ & $(0 \%)$ & & & & & & & & & & & & \\
\hline Total & $\begin{array}{c}165 / 370 \\
(45 \%)\end{array}$ & $\begin{array}{c}148 / 253 \\
(58 \%)\end{array}$ & $\begin{array}{l}15 / 66 \\
(23 \%)\end{array}$ & $\begin{array}{l}2 / 51 \\
(4 \%)\end{array}$ & $\begin{array}{l}22 / 117 \\
(19 \%)\end{array}$ & $\begin{array}{l}17 / 55 \\
(31 \%)\end{array}$ & $\begin{array}{l}5 / 39 \\
(13 \%)\end{array}$ & $\begin{array}{l}0 / 23 \\
(0 \%)\end{array}$ & $\begin{array}{c}9 / 39 \\
(23 \%)\end{array}$ & $\begin{array}{c}9 / 13 \\
(69 \%)\end{array}$ & $\begin{array}{l}0 / 17 \\
(0 \%)\end{array}$ & $\begin{array}{c}0 / 9 \\
(0 \%)\end{array}$ & $\begin{array}{c}0 / 9 \\
(0 \%)\end{array}$ & $\begin{array}{c}0 / 7 \\
(0 \%)\end{array}$ & $\begin{array}{c}0 / 4 \\
(0 \%)\end{array}$ & $\begin{array}{l}0 / 3 \\
(0 \%)\end{array}$ \\
\hline
\end{tabular}

This article is protected by copyright. All rights reserved. 
Table 3: Reasons for discrepancies with AASLD recommendations

\section{First line treatment proposed, No (\%)}

\section{Therapy for the next}

best stage

Standard of care

$0 \quad 205(81 \%)$

$22(34 \%)^{* *}$

$15(29 \%) \S$
Therapy for the next

worst stage

$48(19 \%)^{*}$

36 (54\%)

$8(12 \%)^{* * *}$

27 (53\%)

$9(18 \%)^{\mathrm{s}}$

* 15 TACE for Child-Pugh 7-9, 2 for age > 80 years, 3 for comorbidities (1 previous stroke, 2 previous ischemic heart disease, which intrese anesthesiological risk), 26 for strategical localization, 1 sorafenib for strategical localization and hypovascular pattern, 1 BSC for refusal of any therapy.

**3 OLT after downstaging, 4 resection of nodules $>3 \mathrm{~cm}$ with satellites and 2 for multinodular left lobe localization only, 13 RFTA in nodules $>3 \mathrm{~cm}$ with satellites

***6 sorafenib for hypovascular pattern, 2 BSC for refusal of any therapy

$\S 1$ resection of peripheral nodules with marginal neoplastic portal vein infiltration, 2 RFTA of nodule with peripheral portal vein thrombosis, 3 RFTA in patients with performance status 1, 1 RFTA for localized seeding surgically removed, 4 TACE in nodules with marginal neoplastic portal vein infiltration and 4 TACE for performance status 1

§ 4 BSC for refusal of any therapy, 5 BSC for Child-Pugh B7-9

This article is protected by copyright. All rights reserved. 
Table 4: Predictors of survival by univariate analysis

\begin{tabular}{|c|c|c|c|c|}
\hline \multirow[b]{2}{*}{ Predictors of survival } & \multicolumn{4}{|c|}{$p$ value (*) } \\
\hline & $\begin{array}{c}\text { Total } \\
\text { (No. 370) }\end{array}$ & $\begin{array}{l}\text { BCLC 0-A } \\
\text { (No. 253) }\end{array}$ & $\begin{array}{l}\text { BCLC B } \\
\text { (No. 66) }\end{array}$ & $\begin{array}{l}\text { BCLC C } \\
\text { (No. 51) }\end{array}$ \\
\hline $\begin{array}{l}\text { Age } \\
(<v s \geq \text { median value })^{* *}\end{array}$ & 0.94 & 0.90 & 0.80 & 0.66 \\
\hline $\begin{array}{l}\text { Gender } \\
\text { (Male, Female) }\end{array}$ & 0.67 & 0.94 & 0.30 & 0.76 \\
\hline $\begin{array}{l}\text { Etiology } \\
\text { (HBV, HCV, ETOH, Mixed, Others) }\end{array}$ & 0.08 & 0.22 & 0.74 & 0.018 \\
\hline $\begin{array}{l}\text { Albumin } \\
\text { (<vs } \geq \text { median value })^{* *}\end{array}$ & 0.086 & 0.09 & 0.98 & 0.71 \\
\hline $\begin{array}{l}\text { Bilirubin } \\
\text { (<vs } \geq \text { median value })^{* *}\end{array}$ & 0.025 & 0.83 & 0.33 & 0.11 \\
\hline $\begin{array}{l}\text { INR } \\
(<v s \geq \text { median value })^{* *}\end{array}$ & 0.39 & 0.19 & 0.78 & 0.28 \\
\hline $\begin{array}{l}\text { Creatinine } \\
(<v s \geq \text { median value })^{* *}\end{array}$ & 0.34 & 0.46 & 0.96 & 0.28 \\
\hline $\begin{array}{l}\text { AFP } \\
(0,20-200,>200 \mathrm{ng} / \mathrm{mL})\end{array}$ & 0.0000 & 0.30 & 0.0006 & 0.22 \\
\hline $\begin{array}{l}\text { Ascites } \\
\text { (no vs yes) }\end{array}$ & 0.0004 & 0.004 & 0.18 & 0.77 \\
\hline PSE & 0.0016 & 0.009 & 0.50 & 0.50 \\
\hline
\end{tabular}


(no vs yes)

ECOG PS

$(0,>0)$

0.016

0.21

No. of nodules

$(1,2-3,>3)$

0.0000

0.16

0.93

0.09

Diameter of nodules

( $<v s \geq$ median value)

0.0000

0.04

0.63

0.20

Neoplastic portal vein thrombosis

0.0000

0.63

(no vs yes)

Concordance to AASLD algorithm

(upward, recommended, downward)

0.004

0.0064

0.1384

* = Log-rank test

** = Median reported in table 1

n.a. $=$ not applicable

This article is protected by copyright. All rights reserved. 
Table 5: Independent predictors of survival by multivariate analysis according to Cox Model

\section{HR (95\% C.I), p value}

\begin{tabular}{|c|c|c|c|c|}
\hline Predictors of survival & $\begin{array}{c}\text { Total } \\
\text { (No. 370) }\end{array}$ & $\begin{array}{c}\text { BCLC A } \\
\text { (No. 253) }\end{array}$ & $\begin{array}{l}\text { BCLC B } \\
\text { (No. 66) }\end{array}$ & $\begin{array}{l}\text { BCLC C } \\
\text { (No. 51) }\end{array}$ \\
\hline $\begin{array}{l}\text { Age } \\
(<v s \geq \text { median value })^{* *}\end{array}$ & - & - & - & - \\
\hline $\begin{array}{l}\text { Gender } \\
\text { (Male, Female) }\end{array}$ & - & - & - & - \\
\hline $\begin{array}{l}\text { Etiology } \\
\text { (HBV, HCV, ETOH, Mixed, Others) }\end{array}$ & $1.1(0.9-1.3), 0.51$ & - & - & $1.0(0.8-1.4), 0.73$ \\
\hline $\begin{array}{l}\text { Albumin } \\
(<v s \geq \text { median value })^{* *}\end{array}$ & $0.9(0.6-1.5), 0.83$ & $1.3(0.7-2.6), 0.42$ & - & - \\
\hline $\begin{array}{l}\text { Bilirubin } \\
(<v s \geq \text { median value })^{* *}\end{array}$ & $1.2(0.8-1.9), 0.29$ & - & - & - \\
\hline
\end{tabular}

This article is protected by copyright. All rights reserved. 
INR

$(<v s \geq \text { median value })^{* *}$

\section{Creatinine}

( $<$ vs $\geq$ median value) $* *$

AFP

$(0,20-200,>200 \mathrm{ng} / \mathrm{mL})$

\section{Ascites}

(no vs yes)

PSE

(no vs yes)

ECOG PS

$(0,>0)$

No. of nodules

$(1,2-3,>3)$

Diameter of nodules
$1.8(1.4-2.4),<0.001$

$2.4(1.5-3.9),<0.001 \quad 2.0(1.0-4.1), 0.05$

$1.4(0.8-2.5), 0.28$

$4.0(1.8-9.0), 0.001$

$1.1(1.0-1.2)<0.001$

\author{
$1.7(1.3-2.3),<0.001$
}

$1.9(1.2-3.1), 0.008$
$2.2(0.9-5.8), 0.10$

$2.7(1.6-4.5), 0.001$

(2)

This article is protected by copyright. All rights reserved. 
( $<v s \geq$ median value) ${ }^{*}$

Neoplastic portal vein thrombosis

(no vs yes)

Concordance to AASLD algorithm

(upward, recommended, downward)

$*=$ Log-rank test

** = Median reported in table 1

n.a. $=$ not applicable
$2.6(1.3-4.5), 0.006$

$1.2(0.8-1.6), 0.38$

$2.8(1.3-5.8), 0.006$

$2.9(1.5-5.5) 0.002$

This article is protected by copyright. All rights reserved. 


\section{LEGEND TO FIGURES}

Figure 1: Restaging of HCC according to BCLC classification and treatment-lines

Figure 2: Overall survival curves according to BCLC:

Solid line = BCLC A, median survival 29 months (95\% C.I. 26.0-33.0)

Dotted line $=$ BCLC B, median survival 23.5 months (95\% C.I. 20.1-30.5)

Dashed line $=$ BCLC C. median survival 12 months (95\% C.I. 8.0-18.0).

BCLC A vs B, $\mathrm{p}<0.0001 ;$ BCLC A vs C, $\mathrm{p}<0.0001$; BCLC B vs C, $\mathrm{p}<0.0001$.

Figure 3a: Overall survival curves in BCLC A patients, according to received treatment:

Solid line $=$ Treatment according to AASLD recommendation, median survival 31 months (95\%-C.I. 27.6-35.0)

Dotted line $=$ Downward treatment stage migration. Median survival 21 months $(95 \%$ C.I. 17.8-31.1).

Recommended vs Downward treatment, $\mathrm{p}=0.004$.

Figure 3b: Overall survival curves in BCLC B patients, according to received treatment:

Dashed line $=$ upward treatment stage migration, median survival 33.5 months $(95 \%$ C.I. 25.8-48.1)

Solid line $=$ Treatment according to AASLD recommendation, median survival 21 months (95\% C.I. $17.0-25.0)$

This article is protected by copyright. All rights reserved. 
Dotted line $=$ downward treatment stage migration, median survival 16 months $(95 \%$ C.I. 2.1-30.0)

Upward treatment vs Recommended, $\mathrm{p}=0.029$; Recommended treatment vs Downward, $\mathrm{p}=$ 0.099 .

Figure 3c: Overall survival curves in BCLC C patients, according to received treatment:

Dashed line $=$ Upward treatment stage migration, median survival 21 months (95\% C.I. 11.526.8)

Solid line $=$ treatment according to AASLD recommendation, median survival 9 months (95\% C.I. $4.8-16.0)$

Dotted line $=$ downward treatment stage migration, median survival 14 months $(95 \%$ C.I. 3.0-21.8)

Upward treatment vs Recommended, $\mathrm{p}=0.04$; Recommended treatment vs Downward, $\mathrm{p}=$ 0.43 . 


\section{Figure 1}

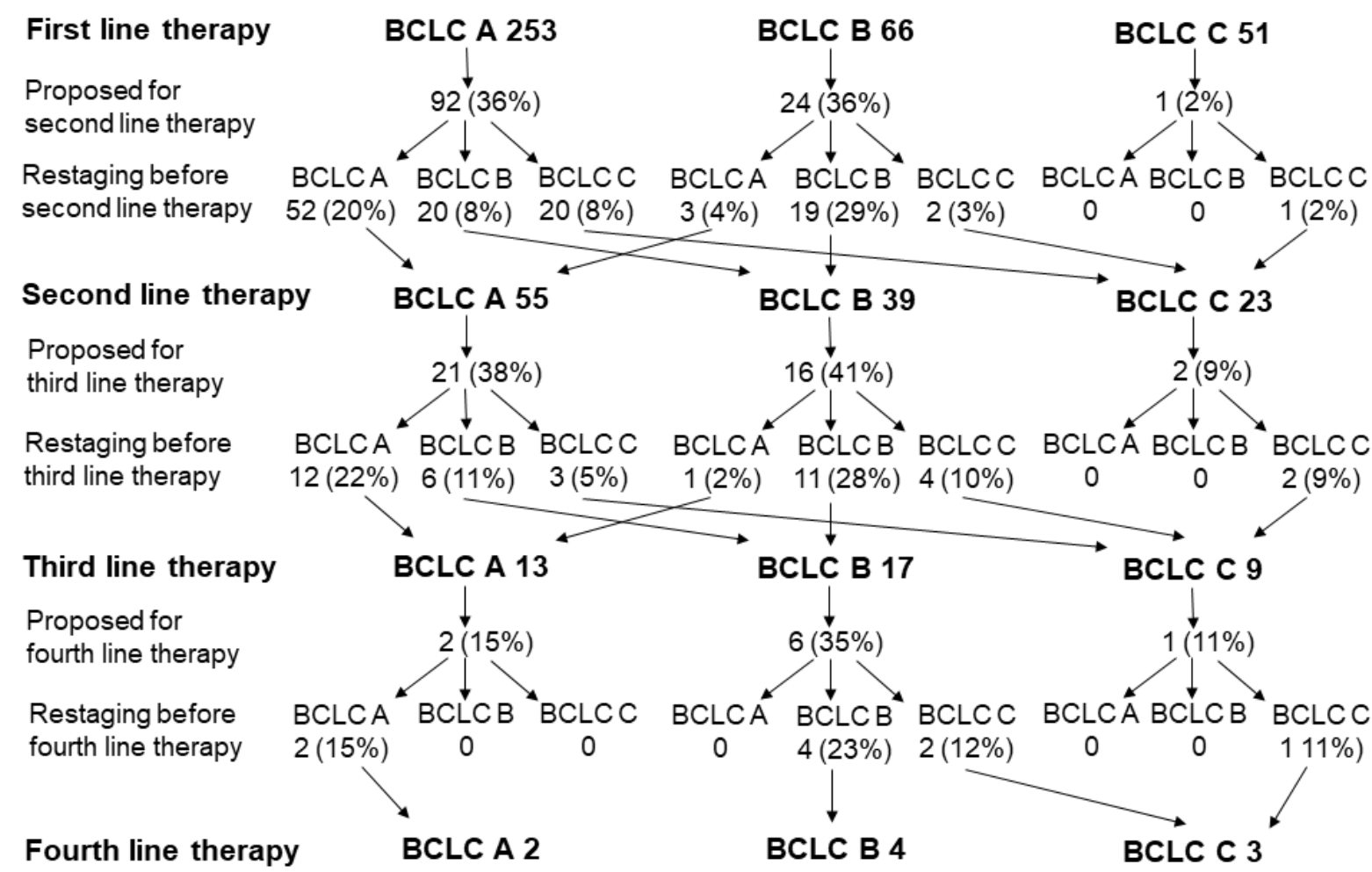

This article is protected by copyright. All rights reserved. 
Figure 2

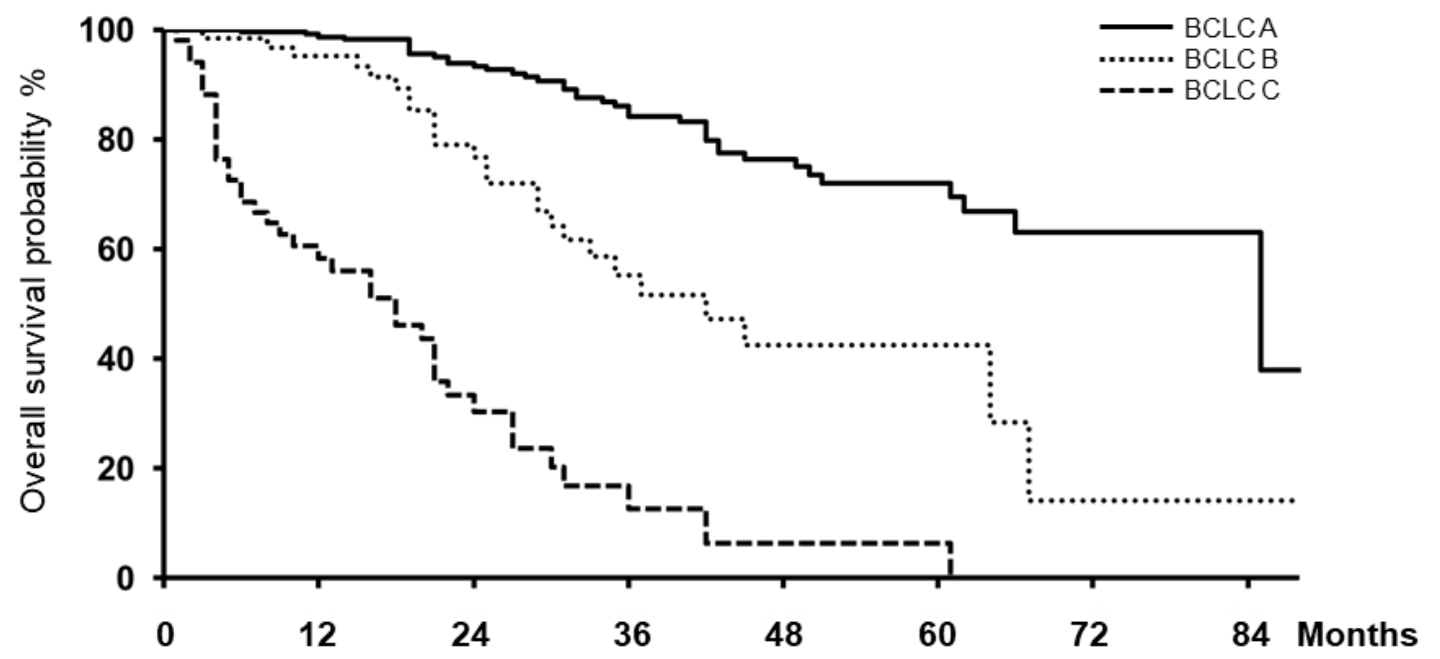

\begin{tabular}{|c|c|c|c|c|c|c|c|}
\hline $\begin{array}{l}\text { Patients } \\
\text { still }\end{array}$ & $\begin{array}{l}\ldots \\
253 \\
\ldots \ldots . . .6\end{array}$ & $\begin{array}{c}215 \\
55\end{array}$ & $\begin{array}{c}155 \\
33\end{array}$ & $\begin{array}{l}96 \\
16\end{array}$ & $\begin{array}{c}55 \\
9\end{array}$ & $\begin{array}{c}30 \\
5\end{array}$ & $\begin{array}{c}10 \\
2\end{array}$ \\
\hline at risk & ----51 & 26 & 11 & 4 & 1 & 1 & \\
\hline
\end{tabular}

This article is protected by copyright. All rights reserved. 
Figure 3a

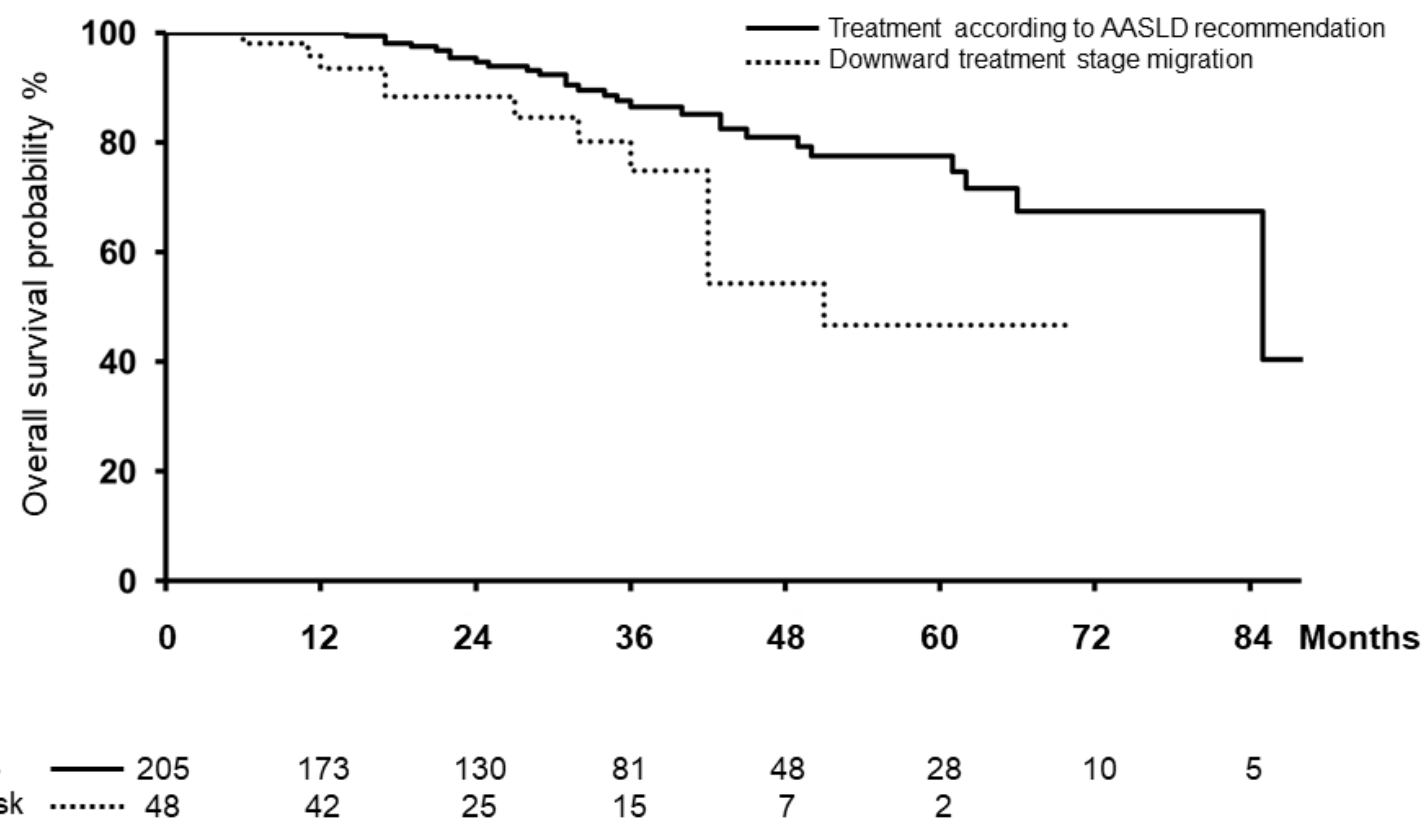

This article is protected by copyright. All rights reserved. 
Figure 3b

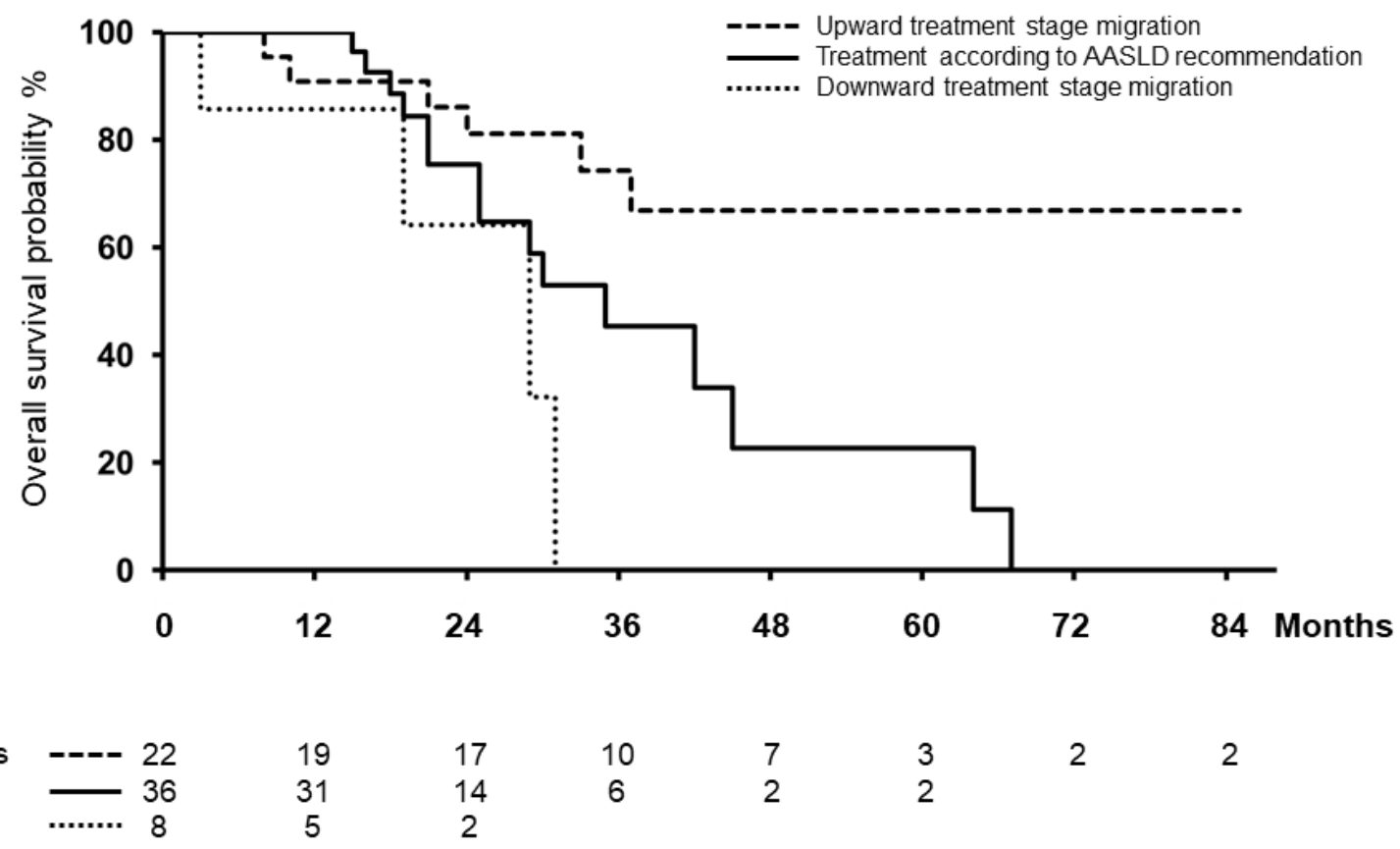

This article is protected by copyright. All rights reserved. 
Figure 3c

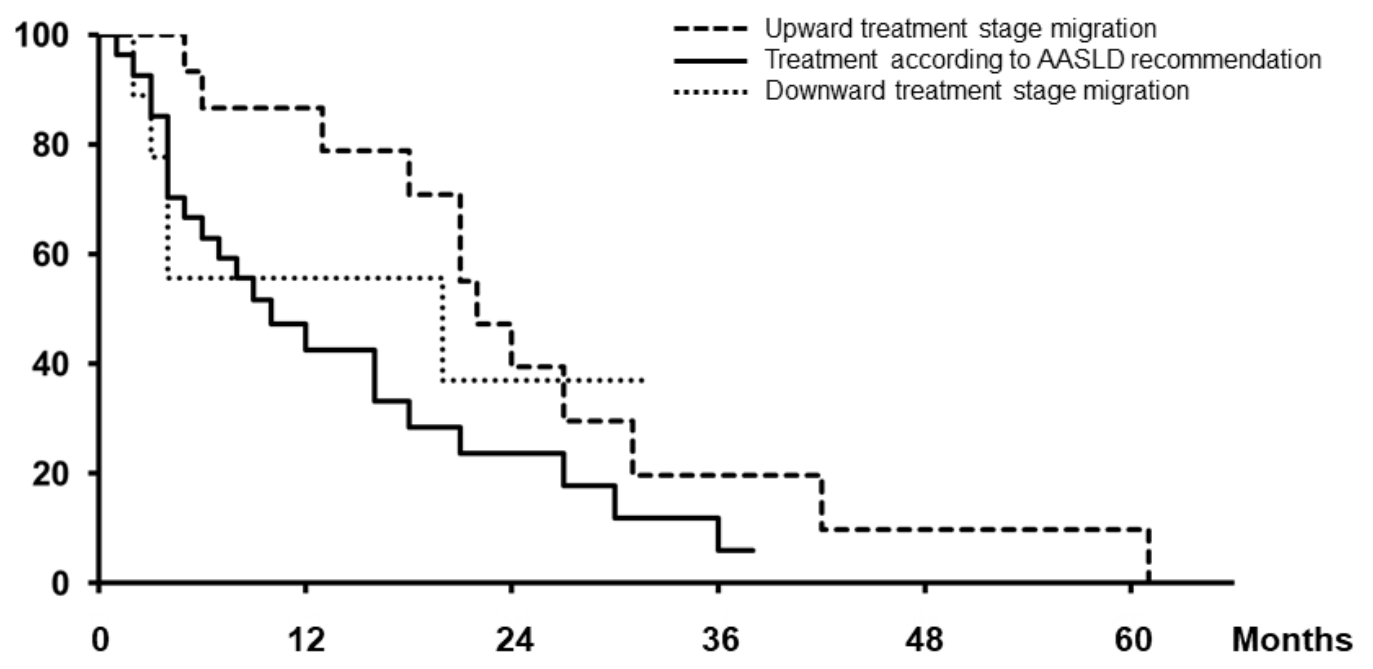

$\begin{array}{lccccccc}\text { Patients } & - & 15 & 11 & 6 & 2 & 1 & 1 \\ \text { still } & \ldots & 27 & 10 & 4 & 2 & & \\ \text { at risk } & \ldots \ldots \ldots & 9 & 5 & 1 & & \end{array}$

This article is protected by copyright. All rights reserved. 